\title{
Study on food preservation materials based on nano-particle reagents
}

\author{
Sumihar HUTAPEA ${ }^{1 *}$ (D), Sarmad GHAZI AL-SHAWI², Tzu-Chia CHEN ${ }^{3}$, Xiang YOU ${ }^{3}$, Dmitry Bokov,5, \\ Walid Kamal ABDELBASSET ${ }^{6,7}$, Wanich SUKSATAN ${ }^{8}$
}

\begin{abstract}
The food industry (FI) is one of the most important parts of any country's industry when it comes to food safety and security. A new approach that can be considered is the use of new technologies in this area. Given the rise in population and per capita food consumption, this sector of the industry should pursue sustainable development through the use of nanotechnologies and increased productivity. In the FI, a number of nanostructured materials (NSMs) have been used, ranging from inorganic metals, metal oxides, and their nanocomposites to nano-organic materials comprising bioactive agents. Given the various advantages of nanotechnology, there are increasing questions concerning its application, as the aggregation of nanoscale materials (NSMs) in human bodies and the atmosphere may pose a variety of health and safety risks. As a result, when producing, handling, intelligently and actively packaging, and using nano-processed food items, safety, and health risks, as well as regulatory policies, must be taken into account. The aim of this analysis is to provide a basic understanding of nanotechnology applications in the food packaging (FP) and processing industries, as well as to recognize possible opportunities and potential risks associated with the usage of NSMs.
\end{abstract}

Keywords: food industry; nanotechnologies; nanostructured materials; bioactive agents.

Practical Application: Food industry should pursue sustainable development through the use of nanotechnologies and increased productivity, because of rise in population and per capita food consumption. In the current study it was tried to review and analysis the food preservation materials based on nano-particle reagents.

\section{Introduction}

Nanotechnology is concerned with the molecular and atomic engineering of matter. Nanomaterials are new and traditional products that have been purposefully nanostructured and are widely utilized in nanotechnology (Zhang et al., 2020; Yaseen et al., 2020). Nanotechnology refers to designing, manufacturing, and applying functional structures with at least one of their characteristic dimensions on the nanometre scale $\left(1 \mathrm{nM}=10^{-9} \mathrm{~m}\right)$. Nanotechnology has introduced tools to humans that can pave the way for a dramatic change in human life by combining materials and controlling processes at the atomic and molecular scales (Seven et al., 2018). This technology is an interdisciplinary approach that, due to its broad scope, has the potential to affect change in a variety of fields. Nanotechnology has been used in a variety of industries, with some industries having reached a fruitful stage and others still in the research and development stage. Agriculture and food processing, aviation and automation, electronics and communications, chemical production, healthcare, life sciences, manufacturing, new energy, the environment, and transportation are some of the industries where nanotechnology is advancing (Qiu et al., 2020; Ruiz-Rico et al., 2018).
Nanotechnology research has advanced significantly in the last decade, and large corporations are now developing new nanoscale materials for a variety of applications. The food industry (FI) is one of the industries that has been slower to adopt this technology thus far, and nanotechnology is a lesser-known issue in this field. This is unsurprising, given that the general public's preference for natural foods has hampered food technology adoption, including nanotechnology. On the other hand, Nanotechnology has potential applications in almost every sector of the FI, according to scientists and industry executives (Melini \& Melini, 2018; Nazir \& Azad, 2019). Food processing (improving the texture or quality of food, production of jelly materials) and food packaging (FP, protection of foods and nutrients against pathogens and harmful gases, nano-sensors in detection) are two of the most important of these sectors. Contamination and evaluation of packaged food, protection of food from ultraviolet rays), with nano-technology being used more frequently in FP. This is most likely due to the fact that the nanoparticles are not added directly to the food, and the food's natural structure is preserved (Kowalewski, 2008; Kumar et al., 2020; Molajou et al., 2021).

\footnotetext{
Received 01 June, 2021

Accepted 17 June, 2021

${ }^{1}$ Faculty of Agriculture, Universitas Medan Area, Medan, Indonesia

${ }^{2}$ Food Science Department, Agriculture College, Basrah University, Basrah, Iraq

${ }^{3}$ Business Administration Program, International College, Krirk University, Bangkok, Thailand

${ }^{4}$ Institute of Pharmacy, Sechenov First Moscow State Medical University, Moscow, Russian Federation

${ }^{5}$ Laboratory of Food Chemistry, Federal Research Center of Nutrition, Biotechnology and Food Safety, Moscow, Russian Federation

${ }^{6}$ Department of Health and Rehabilitation Sciences, College of Applied Medical Sciences, Prince Sattam bin Abdulaziz University, Al Kharj, Saudi Arabia

${ }^{7}$ Department of Physical Therapy, Kasr Al-Aini Hospital, Cairo University, Giza, Egypt

${ }^{8}$ HRH Princess Chulabhorn College of Medical Science, Chulabhorn Royal Academy, Bangkok, Thailand

${ }^{*}$ Corresponding author: SumiharHutapea63@yahoo.com
} 
The use of plastics in modern society is a source of concern. The most difficult aspect of using plastics is recycling them. Plastics are not recyclable or biodegradable and thus pose a serious threat to the environment. Biodegradable materials are currently being considered for use in FP due to their high potential. These materials can be used to replace biodegradable plastics and reduce the damage they cause to the environment. On the other hand, Biodegradable materials are less resistant to water and gas penetration and have lower mechanical properties. Combining biodegradable polymers with other useful materials is one way to solve these issues (Cacciatore et al., 2020; ElSaadony et al., 2021).

One of the most significant aspects of food safety is the packaging. Nanotechnology can help to improve the efficiency and quality of packaging materials, ensuring food safety. Packages of nanoparticles can intelligently respond to environmental conditions or warn consumers about air pollution or toxic substances. In the FP industry, plastics are widely used. However, their effectiveness in blocking the passage of oxygen, water, and carbon dioxide is limited. Plastics containing nanoparticles can improve the permeability of food packages. Clay nanoparticlecontaining packages, for example, have improved mechanical, thermal, and barrier properties, preventing the passage of oxygen, carbon dioxide, and moisture (Boskovic et al., 2019). They also extend the shelf life of food, preserve its color and flavor, and inhibit the growth of microorganisms.

Packaging materials, food safety, bioavailability, distribution mechanisms, disease treatment, emerging methods for molecular and cellular biology, and new materials for pathogen identification are all areas addressed by nanotechnologies in food and agricultural systems (Sekhon, 2010). It would most definitely only be a question of time before we see nanotechnology's goods "on our world." Nanoparticulate distribution systems, packaging (nano-composites bottles, nanolaminates, bins of silver nanoparticles), biosecurity, and food safety are only a few of the uses of nanotechnology in the dairy and FIs (Prakash et al., 2018; Sahoo et al., 2020). In the immediate future, nanotechnology will play a key role in food and dairy production, including two kinds of nano food applications: FP and food additives. FP includes extend food shelf life, eatable, nano coatings which will envelope foods, avoiding gas and humidity exchange, smart packaging for identifying food spoilage and releasing nano-anti-microbes to extend food life span, and nanoscale food additives can be used to affect appearance, taste, nutritional enhancement, provide functionally and also detect pathogens (Pal et al., 2020).

Nanomaterials are commonly used against different microbial pathogens and in crop safety, healthcare, food safety, water treatment, and food security because of their excellent antimicrobial potential and physiochemical function. Nanostructured materials (NSMs) are now being used in the FI as an encapsulated food component, a modern packaging material, and a nanosensor (He et al., 2019; Kim et al., 2018; Mustafa \& Andreescu, 2020).

This study focuses on the use of nanotechnology in the FI, especially nanoparticles and constructed nanostructures. Because the FI has a high capacity for using nanotechnology, this article briefly describes the various types of nanoparticles and their applications. Also, food films, nanoparticles, and nanocomposites as antimicrobial agents in FP, as well as nanosensors, nanocapsules, and nanocomposites, have all been investigated. While green-synthesized NSMs are used in a variety of forms in the FI, their usage has been contentious on a few instances, as NSMs remain technically questionable and may have a long-term adverse impact on human health as well as the climate (Chaturvedi \& Dave, 2020; Hamad et al., 2018). Furthermore, the study addresses existing attempts to correct these flaws and other concerns relevant to nanotechnology growth, awareness, and promotion. Figure 1 depicts a summary of the major applications of nanomaterials/nanoparticles and nanostructures throughout the FI.

\section{Material and methods}

The field of FP was one of the first nanotechnology applications to be commercialized. Nano-packaging is currently used in

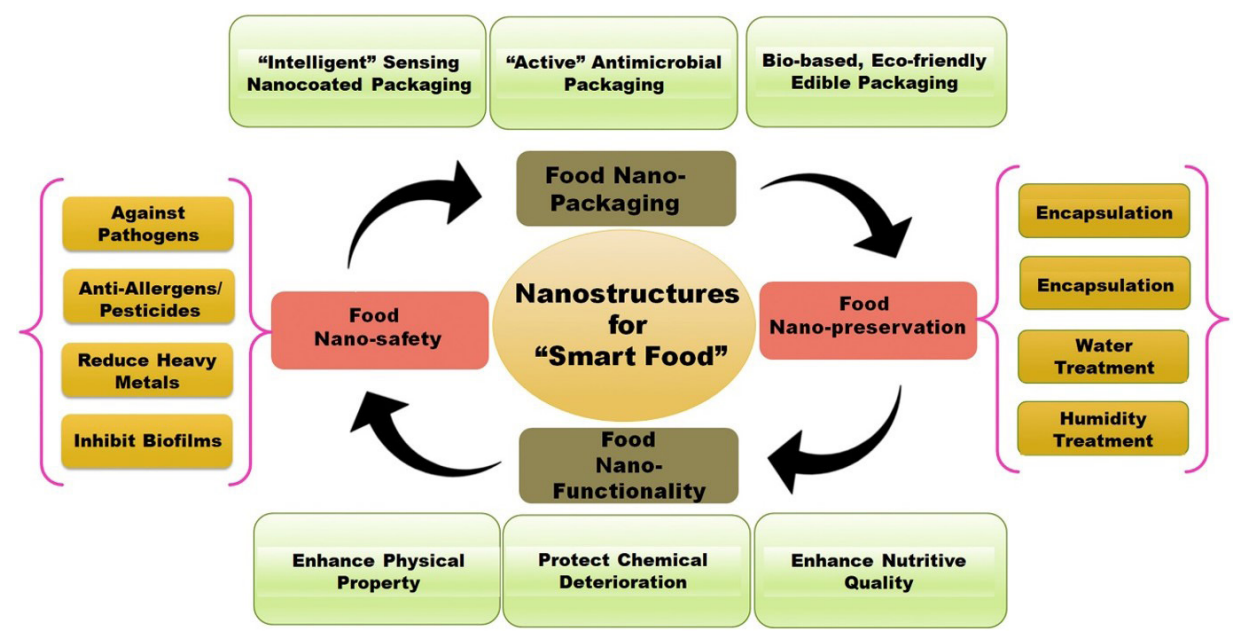

Figure 1. The usage of nanoparticles in different parts of the FI is represented in a systematic way. 
between 400 and 500 food products, according to estimates. Nanotechnology is expected to be used in about $31 \%$ of FP in the next ten years (Chaturvedi \& Dave, 2020).

The primary goal of using nano-packaging is to improve the food's durability and shelf life. Gas, light, and moisture exchange between the outside and inside of the package must all be controlled for this purpose. Antibacterial substances, enzymes, nutrients, and flavors can all be released through nano-packaging (Han et al., 2011; Othman, 2014). The food in the nano-packaging has a longer shelf life as a result of this. Some nano-packages are designed to release substances that neutralize changes in the food inside them, such as moisture changes or an increase in the amount of microbial material inside (such as antibacterial compounds). Silver nanoparticles are currently used in most antibacterial packages, but zinc nanoparticles, magnesium nanoparticles, copper nanoparticles, titanium nanoparticles, and carbon nanotubes will be used in the future (Simbine et al., 2019).

Another application of nanotechnology in the FP industry is the creation of nano-edible coatings. These coatings are as thin as $5 \mathrm{~nm}$ and can't be seen with the naked eye. Meat, fruits, vegetables, cheese, sweets, and bread can all benefit from these coatings. These coatings act as a moisture and gas exchange barrier (Figure 2).

Another type of nanotechnology application in the FP industry is packaging with nanosensors. These packages can assess the temperature and humidity at various times and provide appropriate responses to the consumer based on the circumstances. The color of the packaging, for example, changes as the humidity changes (Bumbudsanpharoke \& Ko, 2015).

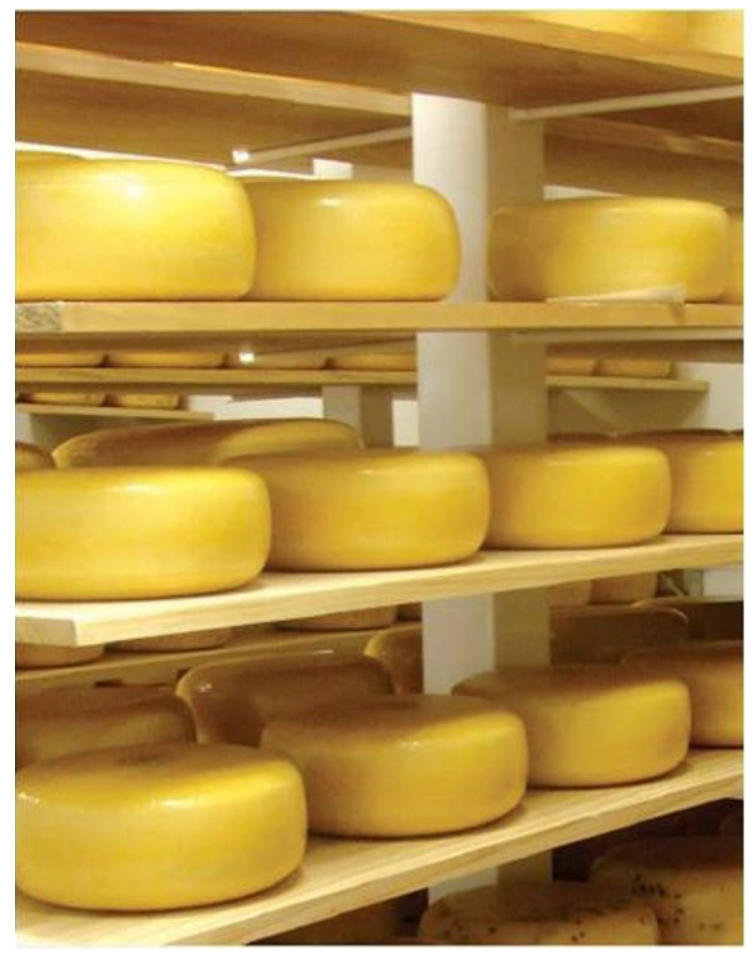

Figure 2. Cheese with nano-edible coatings.
Nano-barcodes are a molecular version of traditional barcodes containing metal nanoparticles with a recognizable and unique chemical fingerprint that machines can detect. These barcodes can be used to protect a brand and evaluate foods that don't have traditional barcodes on them.

Different wavelengths of sunlight are made up of different waves. Some waves are hazardous to our well-being. As a result, they must be kept away from the human body. Ultraviolet waves are one of these dangerous waves. The millet layer blocks these waves from reaching us in nature. One of the issues with transparent packaging is that it transmits ultraviolet radiation to the food when exposed to light. As a result, the food inside does not receive adequate protection and spoils quickly. Plastics containing titanium oxide nanoparticles have been developed using nanotechnology. UV radiation is less harmful when these plastics are used (Rembischevski \& Caldas, 2020).

Some foods are now packaged with plastic. Plastics' main issue is that when they are discarded as waste, they do not decompose and remain in the environment for a long time. This is harmful to the environment. Biological plastic packaging that decomposes in nature is made using nanotechnology. These plastics are eco-friendly because they are made from plants. FP can also benefit from carbon nanotubes. These substances release oxygen and carbon dioxide gas into the atmosphere, causing food to spoil.

\section{Results and discussion}

\subsection{Impermeable polymer nanocomposites}

Composite materials are made up of two or more materials, each with its own set of characteristics. Material is created from the composition of these materials that has the same set of properties as the constituent materials. Reinforced concrete, for example, is a composite material with the hardness of concrete and the flexibility of iron. The use of nanocomposites instead of traditional polymer packaging is one of the fastest-growing areas of nanotechnology. Nanocomposites are made up of a continuous phase of polymeric material and a dispersed phase of nanoparticles. The composite material will be a nanocomposite if the dispersed phase used in the composite, is a nanoparticle. Nanocomposites have a high surface-to-volume ratio, are flexible without sacrificing strength or abrasion resistance, and have desirable optical properties such as particle size transparency. Nanoparticles such as clay, metals, and other materials are used as reinforcements in these composites. In polymer nanocomposites, for example, nanoparticles make up less than $10 \%$ of the total weight. These particles not only increase the strength of polymers but also reduce their weight. FP made of nano-biocomposites not only preserves food and extends its shelf life, but it is also good for the environment (Figure 3). The majority of conventional packaging materials are non-recyclable, contributing to increased pollution.

FP's capacity to function as a gas shield has recently been improved thanks to the usage of nano-bio-composites in FP. Table 1 summarises the different uses of nanoparticles in FP. Biodegradable polymers reinforced with nanofillers, which are eco-friendly, are becoming more common in FP. 

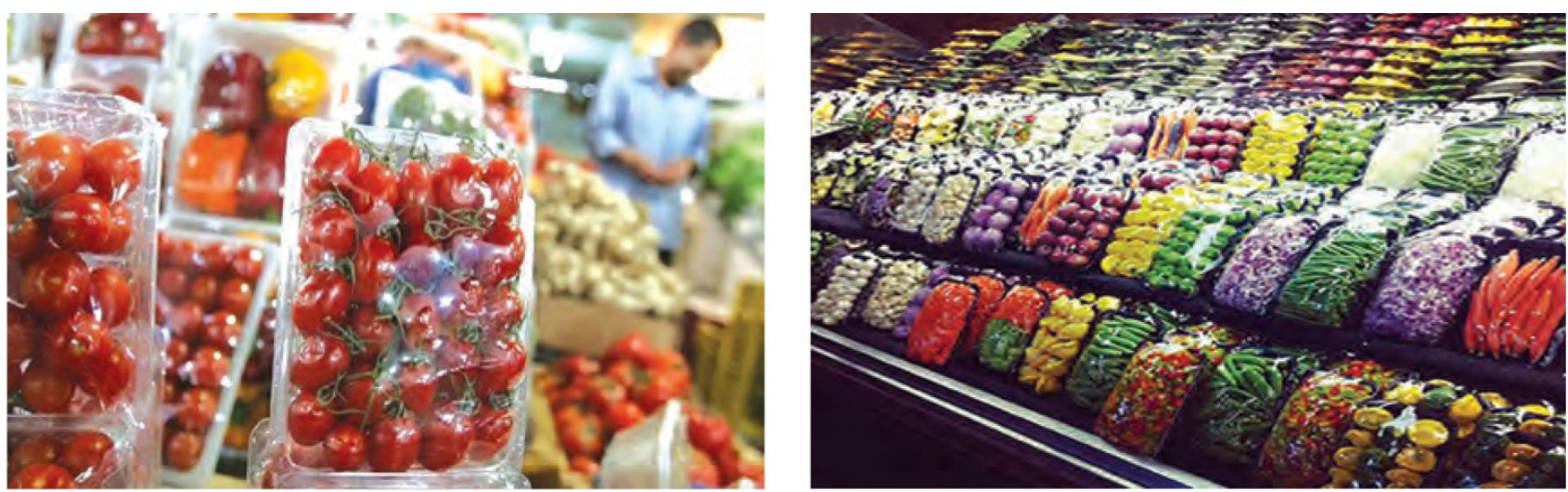

Figure 3. Antibacterial nanocomposites designed for FP.

Table 1. Nanoparticles that may be used in FP.

\begin{tabular}{ccc}
\hline Types of nanoparticles & Matrix & Application \\
\hline Silver oxide & Apple slice & Retards microbial spoilage \\
Titanium oxide & Strawberry, Chinese jujube & Reduces slow-down ripening, browning, decay, and senescence \\
Zinc oxide & Orange juice & $\begin{array}{c}\text { Effectively reduces mold, yeast, Salmonella, and Lactobacillus } \\
\text { Plantarum counts without changes in quality parameters }\end{array}$ \\
Silver & $\begin{array}{c}\text { Retards the growth of aerobic psychrotrophic, yeasts and molds; } \\
\text { Poultry meat, Orange juice, Asparagus. } \\
\text { antimicrobial effect against Escherichia coli and Staphylococcus aureus }\end{array}$ \\
\hline
\end{tabular}

\subsection{Active packaging}

Unlike traditional FP, active FP can react by releasing desirable compounds like antimicrobial and antioxidant agents or removing harmful factors. As a result of these reactions, food stability improves. Relevant molecules in Active packaging have the potential to accumulate or expel materials into or out of the packaged food's natural setting. Currently, active polymer nanomaterials in FP are mostly used in antimicrobial packaging. Different bioactive compounds may be inserted into packing content by capping the material with nanomaterials, capsulation, or using other nano techniques to increase the capabilities and efficacy of food packages (Figure 4).

The following are some notable examples of these FP systems:

\section{Antimicrobial packaging systems}

Antimicrobial packaging systems are rapidly gaining popularity due to their ability to control pathogen and spoilage agent growth in food. These packages are designed to release the preservative as soon as the food inside the package begins to spoil. Antimicrobial systems such as silver nanoparticles are used in FP. Silver has some advantages, such as high-temperature stability and lower volatility, in addition to being toxic to a few microorganisms. The mechanisms of these packages' antimicrobial activity include adhesion to the cell surface, destruction of lipopolysaccharides and the formation of cavities in the cell membrane, penetration into the bacterial cell, DNA damage, and the release of antibacterial silver ions.

\section{Inhibitors of gas and moisture}

The presence of oxygen in FP contributes to the oxidation of fats and oils and the growth of microorganisms. Oxygen also speeds up the processes inside FP that cause discoloration, texture, sharpness, bad taste, and other issues. Ethylene is also a gas that has been linked to the ageing of fruits and vegetables. To extend these products' shelf life, the amount of ethylene in their packaging must be reduced. Nanotechnology can prevent undesirable changes in packaged foods by producing oxygen and ethylene inhibitors, or it can dramatically slow down the rate of quality degradation.

\subsection{Smart packaging}

A system that can communicate with the consumer is referred to as Smart packaging. Smart FP uses a more dynamic way of storing the product and delaying the effects of environmental factors on food. Controlling moisture and oxygen, for example, are two important factors in maintaining the quality of packaged food. Compounds that solve all of the problems associated with increasing or decreasing oxygen and moisture in the packaging are found in smart packaging containers. Thus, one of the characteristics of intelligent packaging materials is their ability to absorb food oxygen, during which time the oxygen in the container space is absorbed, preventing the growth of aerobic microbes and preserving the taste and quality of the food. The passage of carbon dioxide through them is another smart packaging feature. Carbon dioxide can stop germs from growing in foods like red meat, chicken, and cheese. 

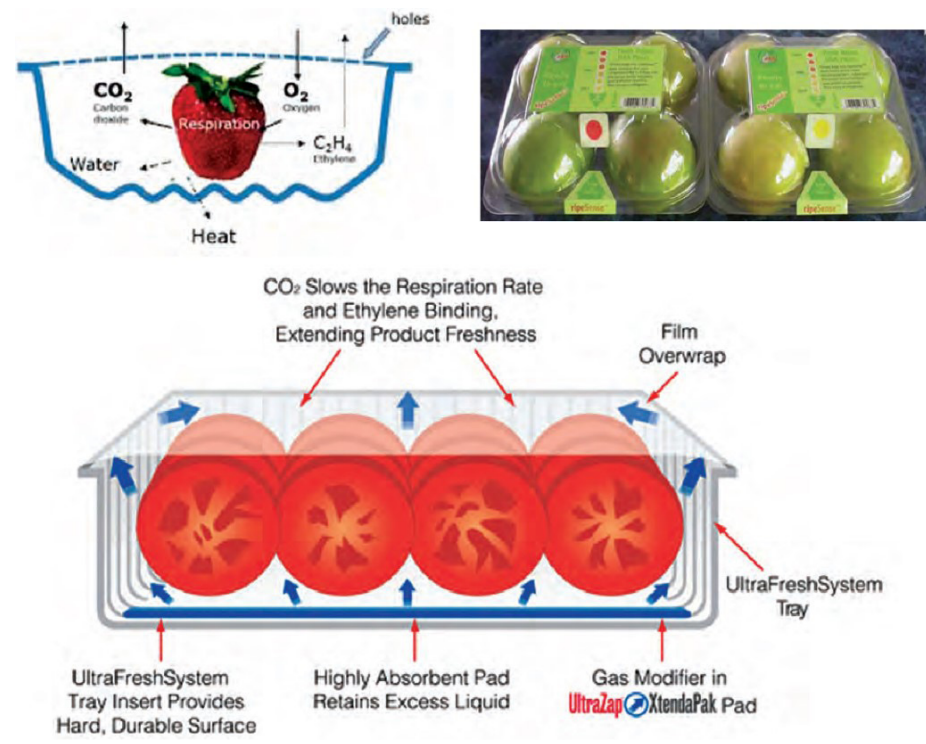

Figure 4. Active packaging technology.
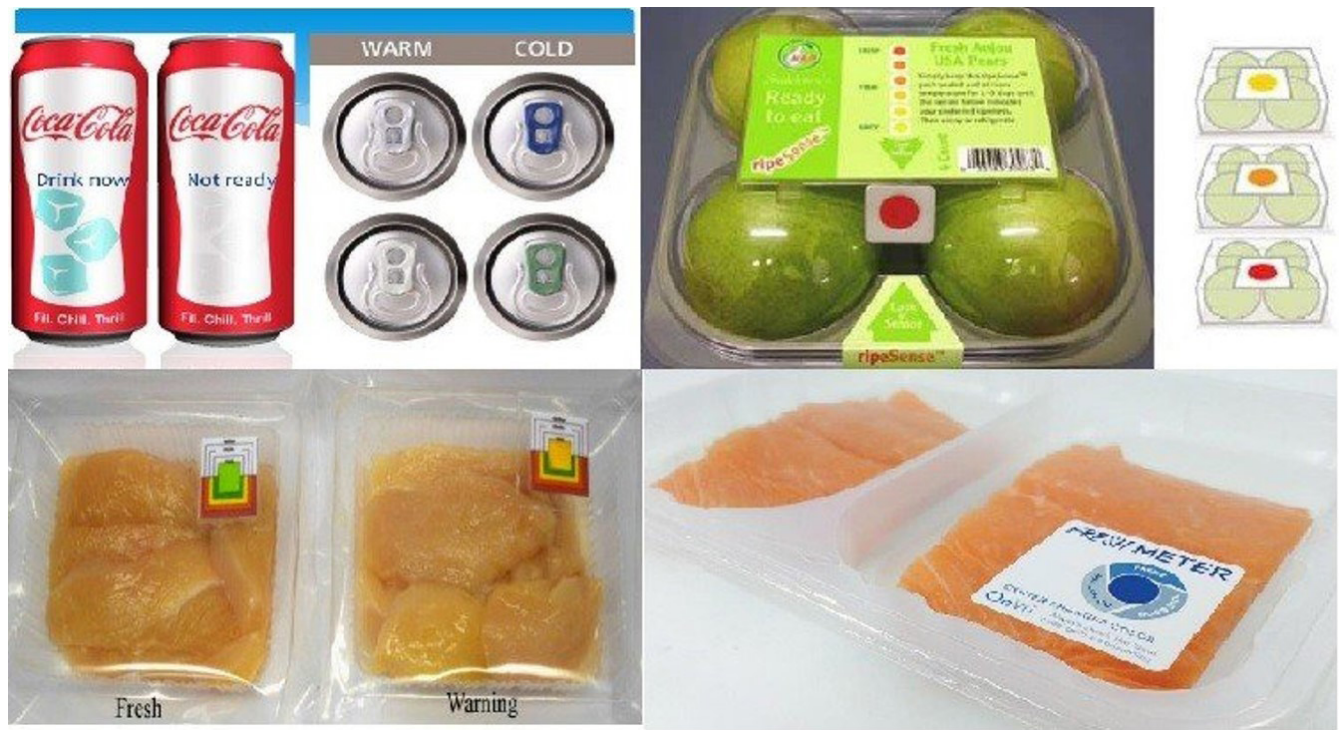

Figure 5. Some examples of smart FP.

Smart packaging is made to identify any microbial or biochemical modifications in food items, as well as pathogen formation. The freshness of the material is detected by sensors in Smart packaging. Smart packaging focuses on reviewing and understanding the status of the product, informing the product's safety and quality (freshness, ripeness, and stability). As a result, smart packaging can track the product and inform the manufacturer, seller, and consumer about its status. Food sensors can detect chemicals, pathogens, and toxins in food when placed in FP. The primary goal of sensor-equipped packaging is to inform the environment inside the package and the status and quality of the product, exchange data with external databases, and provide data for future decisions. A biosensor is one type of sensor that can be used for this purpose. Chemical modification and sensitization of packaging labels, embedding of microchips (smart chips), and placement of nano cells within the label or packaging can all be used to create biosensors (Figure 5).
Smart packaging was therefore created to be used as a food safety monitoring system. Nanotechnology has been employed to develop smart packaging that could significantly increase the storage life and enable it to be shipped over greater distances. The aim of intelligent or smart packaging is to track and relay knowledge about food quality. Time-temperature indicators (TTIs), radiofrequency recognition, and ripeness markers are also part of the system. These smart devices may be embedded in packaging materials or connected to the inside or outside of the package.

\subsection{FP with edible films}

Contaminants from biopolymers have refocused attention on the use of biodegradable materials, and research into biodegradable materials derived from proteins and carbohydrates has expanded significantly over the last two decades. Synthetic 
polymers derived from petroleum products are a good fit for them. Films and food coatings are two types of biodegradable packaging that can be eaten and consumed with food. Before being used in FP, edible films are made in a thin layer and then used as synthetic polymers for packaging. Contrary to popular belief, edible coatings form on food. As a result, the coating is a part of the product and remains on it when it is used, which can be done by waxing, spraying, or immersion. Compared to synthetic polymers, oral films and coatings have distinct advantages. Among the most important benefits of films and food, coatings are biodegradability, excellent inhibition of respiratory gas exchange and thus control of fruit and vegetable respiration, inhibition of odorous and flavourful compound transfer and exchange, and protection of the product against mechanical damage.

\subsection{Antimicrobial agents' organoleptic properties in films and coatings}

Antimicrobial films and coatings for the mouth are an edible component of packaged foods. As a result, the composition of the film or food coating should have no effect on the food's organoleptic properties. Some flavoring compounds, on the other hand, maybe purposefully added to the film or food coating to create an unnatural taste or mask an unpleasant food flavor. To minimize the effect of the film or coating on the taste of the food, it is best to use tasteless food films and coatings. Film-forming biopolymers, emollients, and antimicrobials are the three main components of antimicrobial films, and all three must be tasteless. Soy protein and peanut protein isolated films have a slight bean flavor that is usually not a problem. Tasteless collagen and gelatine films have also been identified. The milk flavor of casein films is acceptable.

Glycerol, sorbitol, and polyethylene glycol are common oral emollients. Glycerol and sorbitol have a pleasant sweetness to them. The sweetness of glycerol in whey protein films, on the other hand, is negligible. Sorbitol has a distinct sweetness to it. Polyethylene glycol has no flavor. Antimicrobials frequently have their own distinct flavor. However, because antimicrobials are present in such small amounts in food films, their impact on taste is negligible and can be overlooked.

\subsection{Nanotechnology's future prospects and emerging threats}

Nanotechnology's use in food science and study has progressed tremendously. Nanotechnology assists in the identification of pollutants, bacteria, pesticides and, as well as the preservation of food safety by monitoring, tracing, and recording. Carbon nanotubes are attracting a lot of popularity as a means to track harmful food spoilage, microorganisms, and proteins by integrating them into packaging materials. Moreover, carbon nanotubes have the ability to turn future FP materials into intelligent devices. Several possible hazards and toxicity issues associated with the use of nanomaterials were identified as a consequence of the never-ending studies on the topic, and these concerns must be resolved. Because of variations in their properties over time, the effect of these nanoscale particles on the atmosphere, livestock, and humans is uncertain. Such nanoparticles may also pass across biological walls, like the blood-brain barrier, to reach different cells and organs.

\section{Conclusion}

As a relatively new technology, nanotechnology has the potential to improve food quality and safety. Foodborne pathogen detection and packaging are two of nanotechnology's most common applications. Because of the modification of the structure of materials at the molecular level, this knowledge has caused a significant change in the packaging industry, and it is now possible to produce them industrially. Important issues must be considered before nanotechnology is widely used in FP. The most crucial is food safety, as nanoparticles can enter food through FP containers. However, because of their ability to cross the cell membrane, more comprehensive research is needed to investigate the long-term effects of different nanoparticles' contact with food on human health. It is concluded that nano-coating has a significant effect on increasing the shelf life of meat products and other products based on the findings, experiments, and parameters measured by the researchers. According to research, nanocoatings, which are a suitable alternative to conventional polystyrene, polypropylene, and other coatings currently used for food storage and packaging, inhibit bacterial growth. Also, waste generated by microorganisms is reduced. The surface-to-volume ratio of nanomaterials is an important property, and many properties of nanomaterials are due to this feature. Nanoscale materials' high surface-to-volume ratio allows them to interact with more biological microorganisms and molecules, demonstrating their antibacterial properties more effectively. As a result, combining nanomaterials in FP is expected to improve packaging barrier properties, reducing the consumption of useful raw materials and producing less waste.

The use of composite polymers to prevent gas and pathogen permeability in FP is a good idea. Clay Polymer nanocomposites are a type of polymer nanocomposites that are popular among users due to features such as low cost and lightweight. These clay nanocomposites are also highly impermeable, which helps to extend food's shelf life. Silver and copper nanocomposites have strong antimicrobial properties and protect food from microbes such as viruses, fungi, and bacteria, extending their shelf life significantly. Nanosensors used in smart packaging can detect gases, odours, chemical contaminants, and pathogens inside FP without destroying it, making them extremely valuable and useful.

Every day, there is further knowledge of the health hazards involved with inhaling ultrafine and nanoparticles. Furthermore, food and human bioaccumulation of nanomaterials such as nanosilver extracted from either nano packaging or plants and animals have been verified. Nanomaterials used as activation catalysts, pesticides, and microbicides often come with an uncertain danger, so risk management protocols must be strictly practiced while handling food. Although with the emergence of nanotechnology, the creation of a safe and sustainable food sector remains a problem. The public should be informed about the wellness, safety, and environmental implications of nanotechnology as it is implemented and integrated into the food chain. 


\section{References}

Boskovic, M., Glisic, M., Djordjevic, J., \& Baltic, M. Z. (2019). Nanotechnology and plant extracts as a future control strategy for meat and milk products. In R. Prasad (Ed.), Plant nanobionics (pp. 201-253). Cham: Springer. http://dx.doi.org/10.1007/978-3-03012496-0_10

Bumbudsanpharoke, N., \& Ko, S. (2015). Nano-food packaging: an overview of market, migration research, and safety regulations. Journal of Food Science, 80(5), R910-R923. http://dx.doi.org/10.1111/17503841.12861. PMid:25881665.

Cacciatore, F. A., Brandelli, A., \& Malheiros, P. S. (2020). Combining natural antimicrobials and nanotechnology for disinfecting food surfaces and control microbial biofilm formation. Critical Reviews in Food Science and Nutrition, 1-12. http://dx.doi.org/10.1080/104 08398.2020.1806782. PMid:32811167.

Chaturvedi, S., \& Dave, P. N. (2020). Application of nanotechnology in foods and beverages. In A. M. Grumezescu \& A. M. Holban (Eds.), Nanoengineering in the beverage industry (pp. 137-162). Amsterdam: Elsevier. http://dx.doi.org/10.1016/B978-0-12-816677-2.00005-3.

El-Saadony, M. T., Sitohy, M. Z., Ramadan, M. F., \& Saad, A. M. (2021). Green nanotechnology for preserving and enriching yogurt with biologically available iron (II). Innovative Food Science \& Emerging Technologies, 69, 102645. http://dx.doi.org/10.1016/j.ifset.2021.102645.

Hamad, A. F., Han, J.H., Kim, B.C., \& Rather, I. A. (2018). The intertwine of nanotechnology with the food industry. Saudi Journal of Biological Sciences, 25(1), 27-30. http://dx.doi.org/10.1016/j.sjbs.2017.09.004. PMid:29379352.

Han, W., Yu, Y., Li, N., \& Wang, L. (2011). Application and safety assessment for nano-composite materials in food packaging. Chinese Science Bulletin, 56(12), 1216-1225. http://dx.doi.org/10.1007/ s11434-010-4326-6.

He, X., Deng, H., \& Hwang, H. (2019). The current application of nanotechnology in food and agriculture. Journal of Food and Drug Analysis, 27(1), 1-21. PMid:30648562.

Kim, D., Kadam, A., Shinde, S., Saratale, R. G., Patra, J., \& Ghodake, G. (2018). Recent developments in nanotechnology transforming the agricultural sector: a transition replete with opportunities. Journal of the Science of Food and Agriculture, 98(3), 849-864. http://dx.doi. org/10.1002/jsfa.8749. PMid:29065236.

Kowalewski, Z. (2008). Actions for small water retention undertaken in Poland. Journal of Water and Land Development, 12(1), 155-167. http://dx.doi.org/10.2478/v10025-009-0012-y.

Kumar, A., Singh, P., Gupta, V., \& Prakash, B. (2020). Application of nanotechnology to boost the functional and preservative properties of essential oils. In B. Prakash (Ed.), Functional and preservative properties of phytochemicals (pp. 241-267). Amsterdam: Elsevier. http://dx.doi.org/10.1016/B978-0-12-818593-3.00008-7.

Melini, V., \& Melini, F. (2018). Strategies to extend bread and GF bread shelf-life: from sourdough to antimicrobial active packaging and nanotechnology. Fermentation, 4(1), 9. http://dx.doi.org/10.3390/ fermentation 4010009 .

Molajou, A., Afshar, A., Khosravi, M., Soleimanian, E., Vahabzadeh, M., \& Variani, H. A. (2021). A new paradigm of water, food, and energy nexus. Environmental Science and Pollution Research International. http://dx.doi.org/10.1007/s11356-021-13034-1. PMid:33634401.

Mustafa, F., \& Andreescu, S. (2020). Nanotechnology-based approaches for food sensing and packaging applications. RSC Advances, 10(33), 19309-19336. http://dx.doi.org/10.1039/D0RA01084G.

Nazir, S., \& Azad, Z. A. A. (2019). Food Nanotechnology: an emerging technology in food processing and preservation. In A. Malik, Z. Erginkaya, \& H. Erten (Eds.), Health and safety aspects of food processing technologies (pp. 567-576). Cham: Springer.

Othman, S. H. (2014). Bio-nanocomposite materials for food packaging applications: types of biopolymer and nano-sized filler. Agriculture and Agricultural Science Procedia, 2, 296-303. http://dx.doi.org/10.1016/j. aaspro.2014.11.042.

Pal, A., Das, R., Kumar, M., \& Roy, D. N. (2020). Application of Nanoscience and Nanotechnology in advancement of safety issues of foods. In M. L. Verma (Ed.), Biotechnological approaches in food adulterants. Boca Raton: CRC Press.

Prakash, B., Kujur, A., Yadav, A., Kumar, A., Singh, P. P., \& Dubey, N. K. (2018). Nanoencapsulation: an efficient technology to boost the antimicrobial potential of plant essential oils in food system. Food Control, 89, 1-11. http://dx.doi.org/10.1016/j.foodcont.2018.01.018.

Qiu, L., Zhang, M., Bhandari, B., \& Yang, C. (2020). Shelf life extension of aquatic products by applying nanotechnology: a review. Critical Reviews in Food Science and Nutrition, 1-15. http://dx.doi.org/10.1 080/10408398.2020.1844139. PMid:33167694.

Rembischevski, P., \& Caldas, E. D. (2020). Risk perception related to food. Food Science and Technology, 40(4), 779-785.

Ruiz-Rico, M., Pérez-Esteve, É., Torre, C., Jiménez-Belenguer, A. I., Quiles, A., Marcos, M. D., Martínez-Máñez, R., \& Barat, J. M. (2018). Improving the antimicrobial power of low-effective antimicrobial molecules through nanotechnology. Journal of Food Science, 83(8), 2140-2147. http://dx.doi.org/10.1111/1750-3841.14211. PMid:29979465.

Sahoo, M., Vishwakarma, S., Panigrahi, C., \& Kumar, J. (2020). Nanotechnology: current applications and future scope in food. Food Frontiers, 2(1), 3-22.

Sekhon, B. S. (2010). Food nanotechnology-an overview. Nanotechnology, Science and Applications, 3, 1-15. PMid:24198465.

Seven, P. T., Seven, I., Baykalir, B. G., Mutlu, S. I., \& Salem, A. Z. (2018). Nanotechnology and nano-propolis in animal production and health: an overview. Italian Journal of Animal Science, 17(4), 921-930. http:// dx.doi.org/10.1080/1828051X.2018.1448726.

Simbine, E. O., Rodrigues, L. C., Lapa-Guimaraes, J., Kamimura, E. S., Corassin, C. H., \& Oliveira, C. A. F. (2019). Application of silver nanoparticles in food packages: a review. Food Science and Technology, 39(4), 793-802. http://dx.doi.org/10.1590/fst.36318.

Yaseen, R., Kotp, Y. H., \& Eissa, D. (2020). The impact of production of silver nanoparticles using soil fungi and its applications for reducing irrigation water salinity. Journal of Water and Land Development, 46, 216-228.

Zhang, J., Hu, S., Du, Y., Cao, D., Wang, G., \& Yuan, Z. (2020). Improved food additive analysis by ever-increasing nanotechnology. Yao $\mathrm{Wu}$ Shi Pin Fen Xi, 28(4), 623-641. http://dx.doi.org/10.38212/22246614.1152. 